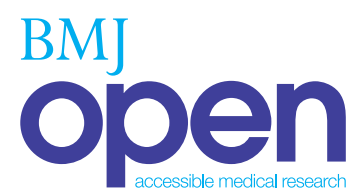

\title{
Is thiazolidinediones use a factor in delaying the need for insulin therapy in type 2 patients with diabetes? A population-based cohort study
}

To cite: Carney GA, Bassett K, Wright JM, et al. Is thiazolidinediones use a factor in delaying the need for insulin therapy in type 2 patients with diabetes? A population-based cohort study. BMJ Open 2012;2: e001910. doi:10.1136/ bmjopen-2012-001910

- Prepublication history for this paper are available online. To view these files please visit the journal online (http://dx.doi.org/10.1136/ bmjopen-2012-001910).

Received 1 August 2012 Accepted 28 September 2012

This final article is available for use under the terms of the Creative Commons Attribution Non-Commercial 2.0 Licence; see http://bmjopen.bmj.com

\footnotetext{
${ }^{1}$ Therapeutics Initiative, University of British Columbia, Vancouver, Canada 2Department of Anesthesiology, Pharmacology and Therapeutics, University of British Columbia, Vancouver, Canada

${ }^{3}$ Department of Family Practice, University of British Columbia, Vancouver, Canada ${ }^{4}$ Department of Medicine, University of British Columbia, Vancouver, Canada
}

Correspondence to Greg Carney; greg.carney@ti.ubc.ca

\author{
ABSTRACT \\ Objective: To understand the independent role of \\ thiazolidinediones (TZDs) in delaying progression to \\ parenteral insulin therapy. \\ Design: Population-based retrospective cohort study. \\ Setting: British Columbia, Canada. \\ Participants: A total of 18867 type 2 diabetes \\ patients (mean age 58.9) treated with metformin as \\ first-line therapy who then switched or added a TZD or \\ sulphonylurea as a second-line treatment between \\ 1 January 1998 and 31 March 2008.
}

Outcome measures: Multivariable Poisson regression models were used to estimate the effect of using TZD compared to sulphonylureas on time to the initiation of insulin treatment (third-line).

Results: The adjusted rate difference in women aged $<60$ showed 2.22 fewer insulin initiation events per 100 person-years (PYs) in the TZD group versus the sulphonylurea group $(95 \% \mathrm{Cl}-3.46$ to -0.99$)$. Men in the same age group had 1.50 fewer insulin initiation events per $100 \mathrm{PYs}$ in the TZD group versus the sulphonylurea group $(95 \% \mathrm{Cl}-2.44$ to -0.56$)$. The average time in days to initiation on insulin in the sulphonylurea, rosiglitazone and pioglitazone group was 343, 252 and 339, respectively. The cumulative hazard for starting insulin for sulphonylurea patients at $12,24,36$ and 48 months was approximately three times higher compared to TZD patients.

Conclusions: Second-line TZD therapy compared to second-line sulphonylurea therapy was associated with a lower incidence of insulin initiation as third-line treatment in patients with type 2 diabetes, with a mean delay of 90 days. This duration of delay must be weighed against the absence of a proven reduction in morbidity or mortality with TZDs and their known serious cardiovascular harm.

\section{INTRODUCTION}

Type 2 diabetes mellitus (T2DM) is a growing problem in North America, ${ }^{1}$ affecting more than 250000 individuals in British Columbia alone (5.6\% of the population).

\section{ARTICLE SUMMARY}

Article focus

- Previous epidemiological studies indicate a greater delay in progression to insulin therapy in patients treated with metformin in combination with a thiazolidinedione (TZD) compared to those treated with sulphonylurea in combination with a TZD, although the magnitude of the delay is unknown.

- This study examines the incidence and magnitude of the delayed progression of insulin therapy in patients receiving second-line TZD treatment versus those receiving second-line sulphonylurea treatment.

Key messages

- Current treatment guidelines for type 2 diabetes mellitus (T2DM) in Canada recommend treatment options designed to attain specific target $\mathrm{HbA1cs}$, a strategy weakly associated with morbidity and mortality evidence.

- Second-line TZD therapy compared to secondline sulphonylurea therapy was associated with a lower incidence of insulin initiation as third-line treatment in patients with T2DM, with a mean delay of 90 days.

- Despite these findings, further research is needed to assess the benefits and known cardiovascular risks of TZDs before using this therapeutic option to meet $\mathrm{HbA1c}$ goals.

Strengths and limitations of this study

- The comprehensive BC administrative health claims database rates relatively high in data quality.

- Baseline characteristics of the study cohorts indicate some imbalance in income and cardiovascular history that may indicate residual confounding.

- Due to BC PharmaCare's limited coverage reimbursement of TZDs versus full coverage of sulphonylureas, wealthier patients were more likely to pay out of pocket for TZDs than lower income patients. 
Prescription drug treatment for T2DM is a substantial healthcare cost burden, especially as patient's progress to treatment with insulin. ${ }^{2}$ Recent studies found $25 \%$ of T2DM patients were prescribed insulin within 6 years of starting oral antidiabetic drug therapy, rising to $42 \%$ after 10 years. ${ }^{3}{ }^{4}$ Current treatment guidelines for T2DM in Canada, which are not without controversy, ${ }^{5}$ recommend initiating metformin as first-line drug therapy based on a reduction in cardiovascular morbidity and mortality and adding oral antidiabetic agents and eventually insulin to attain specific target haemoglobin $(\mathrm{Hb})$ Alcs, a strategy weakly associated with morbidity and mortality evidence. ${ }^{6}{ }^{7}$ From 1998 to 2007 , approximately $80 \%$ of patients with T2DM in British Columbia started metformin as first-line drug therapy. ${ }^{8}$

Thiazolidinediones (TZDs) are a class of drugs that improve cell 'sensitivity' to endogenous insulin. Rosiglitazone (ROS) and pioglitazone (PIO) are two TZDs that have been shown to decrease fasting plasma glucose and HbAlc levels in patients with T2DM. ${ }^{9}$ In addition, ROS delayed the time to diagnosis of diabetes compared placebo in patients with mild hyperglycaemia and impaired glucose tolerance tests. ${ }^{10}$ ROS also delayed the time to monotherapy failure compared to metformin or glyburide, but at the cost of an increased risk of congestive heart failure. ${ }^{11}$

In more advanced disease, epidemiological studies have reported a slower progression to insulin in patients receiving metformin in combination with a TZD compared with those receiving a sulphonylurea in combination with a TZD. ${ }^{12}$ In a retrospective analysis of the Texas Medicaide database, Rascati et al compared three cohorts of patients who received combination oral antidiabetic therapy. They showed that patients in the sulphonylurea+TZD cohort had a $40 \%$ higher probability of more rapid progression to insulin (203/773) than patients who received combination metformin+TZD $(85 / 438)$. Further research is needed to understand the magnitude of the delay to insulin initiation, particularly for patients needing second-line therapy.

We investigated the association between insulin initiation in patients with T2DM and second-line treatment with ROS, PIO or sulphonylureas in patients who initiated metformin as first-line pharmacotherapy. We required first-line metformin use as a way of controlling for confounding by indication. Similarly, we chose second-line sulphonylurea patients as a comparison group because the severity and course of their diabetes was expected to be similar to patients who were prescribed a TZD. Confounding by indication is one of the most widespread threats to validity in epidemiological observational analysis, ${ }^{13}$ occurring when the exposure is associated with disease severity.

The $\mathrm{ACCORD}^{14}$ and $\mathrm{UGDP}^{15}$ trials found intensive hypoglycemic therapy attempting to achieve lower HbA1c levels is associated with an increase in morbidity and mortality. These studies highlight the importance of validating HbAlc targets in terms of serious morbidity and mortality before accepting them as treatment goals. This is particularly important with TZDs where paradoxically HbA1c was significantly decreased and serious cardiovascular morbidity was significantly increased in patients taking ROS. ${ }^{16}$

We expected second-line ROS and PIO to delay the use of insulin compared to second-line sulphonylureas, in patients with T2DM who initiated metformin as firstline therapy. However, the incidence and magnitude of that delay, especially in newly diagnosed patients, needed to be quantified to better weight that benefit versus known serious harm.

\section{METHODS \\ Data}

All prescriptions dispensed at community pharmacies in British Columbia since the autumn of 1995 are stored in a central database named PharmaNet. The system captures dispensing data and performs quality checks every time prescriptions are filled. It is believed that those features keep under-reporting and misclassification is very low. Prescriptions are linked by unique personal health number to BC Ministry of Health databases for hospitalisations, medical services and medical services registration. The Canadian Institute for Health Information collects hospital discharge records from all Canadian provinces, including Ontario where the data have been evaluated for accuracy. ${ }^{17}$ Similar administrative claims databases in other North American jurisdictions have been studied for accuracy and completeness ${ }^{18-21}$ but we are unaware of any such analyses in British Columbia. We had ethics approval from the University of British Columbia Clinical Research Ethics Board (Certificate no. H02-70020).

\section{Study population}

The source population for the study was all BC residents between January 1998 and March 2008 who were registered in the provincial universal medical services plan. Federally insured patients such as aboriginals, federal police officers and members of the armed forces and their families were excluded from the source population because we did not have the permission to use those data. Excluded patients composed about $7 \%$ of the provincial population. The source population numbered 4.01 million in $2007 .{ }^{22}$

\section{Study design and cohort}

We conducted a retrospective cohort study. We extracted patients from the source population who initiated metformin between 1 January 1998 and 31 March 2008 and then added or switched to a TZD (ROS or PIO) or a sulphonylurea (acetohexamide, chlorpropamide, gliclazide, glimepiride, glyburide, tolbutamide) as second-line therapy. We chose second-line sulphonylurea patients as a comparison group because the severity and course of their diabetes was expected to be most similar to other 
second-line patients who were prescribed a TZD instead. We assigned an index date equal to the first prescription dispensed date of a TZD or sulphonylurea.

\section{Study outcome}

Our outcome was the occurrence of first insulin prescription after exposure to a TZD or sulphonylurea. The outcome was identified by the presence of a dispensing for insulin in the PharmaNet database. Patients were censored at the earliest occurrence of our study outcome, death, end of the study period (31 March 2008), entry into a long-term care facility, emigration from BC, therapy discontinuation (no further prescriptions for 60 days after the end of a drug dispensing) or crossover to the other treatment arm.

\section{Data analysis}

Multivariable Poisson regression models were used to estimate the effect of TZD therapy on initiation of insulin treatment compared to sulphonylureas. In three regressions with sulphonylurea patients as controls we estimated rates of insulin initiation, and adjusted rate ratios and rate differences for three contrasts with sulphonylurea patients: ROS, PIO and TZD (defined as ROS or PIO). We constructed a cumulative hazard plot for insulin initiation in each exposure category. Rate differences per 100 person-years (PYs) were calculated in four categories: men, women, age $>=60$ and age $<60$.

\section{Confounders}

Potential confounders were measured before exposure to a sulphonylurea (SU) or TZD using diagnostic codes, procedure codes, prescription claim records and Ministry of Health Services' patient demographic data. Our analysis included the following potential confounders: age (10-year age groups), sex, family income (quintiles) and index year of treatment initiation. The following covariates were included in the outcome model if within 5 years prior to index date: renal disease (ICD-9 584-586, 403-404), acute myocardial infarction, AMI (ICD-9 410 or 412), angina (ICD-9 411, 413), congestive heart failure (hospitalisation for ICD-9 425 or 428, or a physician visit for same plus a prescription for furosemide), coronary artery bypass graft (hospitalisation for procedure codes $481,4811-4817,4819$ ), transient ischaemic attack (hospitalisation for ICD-9 435), coronary catheterisation (hospitalisation for procedure codes 4802 or 4803) and percutaneous transluminal coronary angioplasty (hospitalisation for procedure codes 4892-4898 or 4995-4997). Prior use of the following covariates was included in the model if within 2 years of the index date: exposure to statins, digoxin, ACE inhibitors, Cox-2 inhibitors, diuretics, clopidogrel, ACE inhibitors or angiotensin receptor blockers, spironolactone or $\beta$-blockers. The following covariates were examined but excluded based on $p$ values greater than 0.2 in univariate tests: prior osteoarthritis (ICD-9 715), peripheral vascular disease (ICD-9 440440.9), exposure to non-coxib NSAIDs, all NSAIDs, calcium channel blockers, metformin, benzodiazepines and bisphosphonates.

\section{Sensitivity analysis}

A sensitivity analysis was performed comparing the TZD cohort versus the sulphonylurea cohort using Schneeweiss et al's method of High-Dimension Propensity Score (HDPS) comorbidity adjustment. The high-dimensional approach to generating propensity scores is an automated data-driven approach to analysing the administrative claims database for variables that appear to be confounders. The HDPS algorithm searches the database to find variables that serve as proxies for previously unmeasured confounders by measuring potential to bias the exposure/ outcome relationship. The HDPS methods have been previously described in detail here. ${ }^{23}$ Poisson regression was used, adjusting for propensity score deciles.

\section{RESULTS}

There were 21230 patients from the source population who initiated metformin as first-line therapy and then added or switched to either an SU or TZD between 1 January 1998 and 31 March 2008. Of those, 18867 patients $(89 \%)$ remained eligible for cohort entry after excluding patients who were admitted to a long-term care facility $(n=245)$, diagnosed with gestational diabetes in the previous 2 years $(n=24)$, had invalid data for sex or date of birth $(\mathrm{n}=13)$ or had less than 2 years of provincial health plan coverage prior to index $(\mathrm{n}=2098)$. In total, 2363 distinct patients were excluded.

Characteristics of cohort patients are shown in table 1 . The patients in the study averaged 58.9 years old and TZD patients were 3.7 years younger on average than SU patients. The proportion of patients who were women was similar in all groups (SU 45\%, any TZD 45\%, PIO $46 \%$ and ROS 45\%). Income data were available for $87 \%$ of patients in the 'Any TZD' cohort and for $81 \%$ of patients in the SU cohort. A total of $12 \%$ of patients in the 'Any TZD' cohort were in the highest income, indicating that TZD patients earned significantly more than SU patients. The Romano Score is a comorbidity index based on ICD-9 outpatient and inpatient diagnoses. ${ }^{24}$ Mean Romano comorbidity scores indicated that SU patients had slightly more comorbid disease (mean Romano score 1.75) compared to TZD patients (mean Romano score 1.42); however, the median diabetes duration was 3 years in each of the four cohorts.

The SU group had higher rates of renal disease, AMI, angina, congestive heart failure and coronary catherisation in the 5-year period prior to the index date, (absolute range $2-5 \%$ higher). Medication history was similar in all groups in the 2-year period prior to the index date. PIO patients had a lower proportion of congestive heart failure (7.5) compared to ROS patients (9.4). Baseline characteristics were otherwise similar between ROS patients and PIO patients. 
Table 1 Baseline characteristics of study patients by current exposure to thiazolidinediones or sulphonylureas in British Columbia (1998-2007)

\begin{tabular}{|c|c|c|c|c|}
\hline Variable & $\begin{array}{l}\text { Sulphonylurea } \\
(\mathrm{N}=15613)\end{array}$ & $\begin{array}{l}\text { Any TZD } \\
(\mathrm{N}=3254)\end{array}$ & $\begin{array}{l}\text { Pioglitazone } \\
(\mathrm{N}=1213)\end{array}$ & $\begin{array}{l}\text { Rosiglitazone } \\
(\mathrm{N}=2041)\end{array}$ \\
\hline Age, median (IQR) & $60(50,69)$ & $56(48,64)$ & $56(48,64)$ & $56(48,64)$ \\
\hline Women (\%) & $6952(45)$ & $1479(45)$ & $556(46)$ & $923(45)$ \\
\hline \multicolumn{5}{|l|}{ Family income $(\%)^{*}$} \\
\hline$\$ 0-\$ 21250$ & $3600(23)$ & $377(12)$ & $139(11)$ & $238(12)$ \\
\hline$\$ 21251-45000$ & $4211(27)$ & $783(24)$ & $288(24)$ & $495(24)$ \\
\hline$\$ 45001-\$ 70833$ & $2634(17)$ & 761 (23) & $280(23)$ & $481(24)$ \\
\hline$\$ 70834-\$ 97500$ & $1260(8)$ & $511(16)$ & $178(15)$ & $333(16)$ \\
\hline$>\$ 97500$ & $935(6)$ & $393(12)$ & $149(12)$ & $244(12)$ \\
\hline Unknown & $2973(19)$ & $429(13)$ & $179(15)$ & $250(12)$ \\
\hline Romano comorbidity score, median (IQR)† & $1.00(1,3)$ & $1.00(1,2)$ & $1.0(1,2)$ & $1.0(1,2)$ \\
\hline Diabetes duration in years, median (IQR) & $3(1,7)$ & $3(1,6)$ & $3(1,7)$ & $3(1,6)$ \\
\hline \multicolumn{5}{|l|}{ Medical history } \\
\hline Renal disease & $637(4)$ & $75(2)$ & $25(2)$ & $50(2)$ \\
\hline Acute myocardial infarction $\ddagger$ & $912(6)$ & $104(3)$ & $40(3)$ & $64(3)$ \\
\hline Anginał & $3693(24)$ & $639(20)$ & $241(20)$ & $398(20)$ \\
\hline Congestive heart failure $\ddagger$ & $2211(14)$ & $282(9)$ & $91(8)$ & $191(9)$ \\
\hline Coronary catheterization $\ddagger$ & $1024(7)$ & $176(5)$ & $70(6)$ & $106(5)$ \\
\hline \multicolumn{5}{|l|}{ Lab tests in past two years $\S$} \\
\hline $\mathrm{HbA} 1 \mathrm{c}, \mathrm{n}$ & $14525(93)$ & $3057(94)$ & $1124(93)$ & $1933(95)$ \\
\hline HbA1c, median (IQR) & $3(2,5)$ & $3(2,5)$ & $4(2,6)$ & $3(2,5)$ \\
\hline Fasting blood glucose, $n$ & $14521(93)$ & $3041(93)$ & $1129(93)$ & $1912(94)$ \\
\hline Fasting Blood Glucose, median (IQR) & $3(2,5)$ & $3(2,5)$ & $3(2,5)$ & $3(2,5)$ \\
\hline \multicolumn{5}{|l|}{ Drug use in past two years } \\
\hline Metformin & $15393(99)$ & 3211 (99) & $1193(98)$ & 2018 (99) \\
\hline ACE inhibitor & $6923(44)$ & $1448(44)$ & $531(44)$ & $917(45)$ \\
\hline$\beta$-Blockers & $11279(72)$ & $2512(77)$ & $940(77)$ & $1572(77)$ \\
\hline Calcium channel blockers & $2854(18)$ & $487(15)$ & $176(15)$ & $311(15)$ \\
\hline Coxib NSAIDs & $1260(8)$ & $334(10)$ & $111(9)$ & $223(11)$ \\
\hline NSAIDs & $5511(35)$ & $1059(33)$ & $394(32)$ & $665(33)$ \\
\hline Digoxin & $609(4)$ & $63(2)$ & $18(1)$ & $45(2)$ \\
\hline Spironolactone & 609 (4) & $100(3)$ & $36(3)$ & $64(3)$ \\
\hline Statins & $6682(43)$ & $1475(45)$ & $544(45)$ & $931(46)$ \\
\hline \multicolumn{5}{|c|}{$\begin{array}{l}\text { *Net family income in Canadian\$ from the most recent Income tax return (1 Canadian\$" } 1 \text { US\$). } \\
\text { †Romano comorbidity score calculated using data one year prior to the index date. } \\
\text { fHistory within five years prior to the index date. } \\
\text { \$MSP (medical services plan) fee items used-HbAlc: } 91745 \text {, fasting blood glucose: } 91705-91710,91715-91717 \text { and } 91719 . \\
\text { qDispensing of drug within } 730 \text { days prior to index date. } \\
\text { TZD, thiazolidinedione. }\end{array}$} \\
\hline
\end{tabular}

The cumulative hazard for starting insulin for sulphonylurea patients at 12, 24, 36 and 48 months was approximately three times higher compared to TZD patients (figure 1). The difference in the cumulative hazard distribution of insulin use between TZD and SU patients suggests the association is not modified over time and is amenable to modelling using Poisson regression.

Table 2 shows the number of events, PYs of follow-up and event rates for insulin initiation in each of the treatment arms. We identified 563 total events of insulin initiation in the cohorts during follow-up. The average time in days to initiation on insulin in the SU, ROS and PIO group was 343, 252 and 339, respectively. Average follow-up times were similar among treatment groups (0.90 years SU, 1.09 years TZD, 1.09 years ROS and 1.04 years $\mathrm{PIO})$.
The incidence rate among women was nearly three times higher in the SU group (4.21 events per $100 \mathrm{PYs}$ ) compared to PIO (1.42 events per $100 \mathrm{PYs}$ ), and was 2.7 times higher than the ROS group (1.56 events per 100 PYs). Men taking SUs were over 2.3 times more likely to initiate insulin than men prescribed TZDs (3.05 events per $100 \mathrm{PYs}$ versus 1.30 events per $100 \mathrm{PYs}$, respectively).

Adjusted rate differences from our multivariable Poisson regressions for men and women by age group are shown in table 3 . The adjusted rate difference in women aged $\geq$ showed 1.18 fewer insulin initiation events per 100 PYs in the TZD group versus the SU group (95\% CI -2.05 to -0.32$)$. Men in the same age group had 0.80 fewer insulin initiation events per $100 \mathrm{PYs}$ in the TZD group versus the SU group (95\% CI -1.51 to -0.08$)$. In the under 60 age group, the adjusted rate difference per 
Figure 1 Cumulative hazard distribution for time to insulin end points associated with thiazolidinediones or sulphonylureas in patients with type 2 diabetes mellitus.

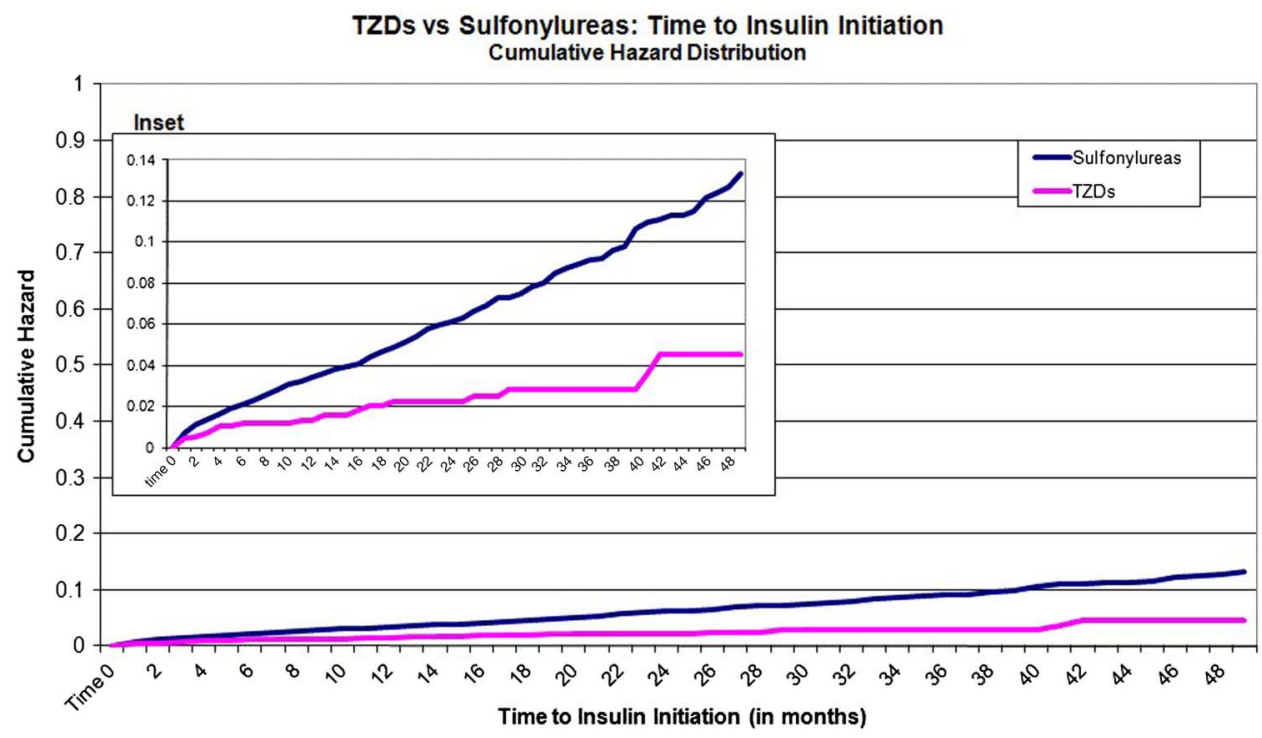

TZDs vs Sulfonylureas: Time to Insulin Initiation

Cumulative Hazard Distribution

Time to Insulin Initiation (in months)
100 PYs in women and men were -2.22 (95\% CI -3.46 to $-0.99)$ and $-1.50(95 \%$ CI -2.44 to -0.56$)$, respectively, when comparing SU versus TZDs. When exposure to each TZD was estimated separately, similar adjusted rate differences in both men and women and in both age groups were found.

The results of the HDPS sensitivity analysis showed a statistically significant $62 \%$ lower probability of insulin initiation in the TZD group compared to the sulphonylureas (adjusted HR 0.38, 95\% CI 0.28 to 0.51 ). The c-statistic of the HDPS model discrimination was 0.72 .

\section{DISCUSSION}

This retrospective cohort study followed T2DM patients who initiated metformin, then added or switched to

Table 2 Insulin events with thiazolidinediones (TZDs) or sulphonylureas in patients with type 2 diabetes mellitus

\begin{tabular}{|c|c|c|c|c|}
\hline Sex & Drug group & $\begin{array}{l}\text { Person } \\
\text { years of } \\
\text { follow-up }\end{array}$ & $\begin{array}{l}\text { Insulin } \\
\text { initiation } \\
\text { events }\end{array}$ & $\begin{array}{l}\text { Events } \\
\text { per } \\
100 \text { PYs }\end{array}$ \\
\hline \multirow[t]{4}{*}{ Men } & Sulphonylurea & 7879 & 240 & 3.05 \\
\hline & TZDs & 2005 & 26 & 1.30 \\
\hline & Rosiglitazone & 1250 & 15 & 1.20 \\
\hline & Piogl itazone & 722 & 11 & 1.52 \\
\hline \multirow[t]{4}{*}{ Women } & Sulphonylurea & 6491 & 273 & 4.21 \\
\hline & TZDs & 1633 & 24 & 1.47 \\
\hline & Rosiglitazone & 1027 & 16 & 1.56 \\
\hline & Piogl itazone & 562 & 8 & 1.42 \\
\hline \multirow{4}{*}{$\begin{array}{l}\text { Men } \\
\text { and } \\
\text { women }\end{array}$} & Sulphonylurea & 14369 & 513 & 3.57 \\
\hline & TZDs & 3638 & 50 & 1.37 \\
\hline & Rosiglitazone & 2277 & 31 & 1.36 \\
\hline & Piogl itazone & 1285 & 19 & 1.48 \\
\hline
\end{tabular}

second-line SU ( $\mathrm{n}=15613)$, second-line PIO $(\mathrm{n}=1213)$, second-line $\operatorname{ROS}(\mathrm{n}=2041)$ or second-line PIO or ROS $(n=3254)$. We found a lower rate of insulin initiation in the PIO, ROS and any TZD cohorts compared to SU for both men and women, age $<60$ and age $\geq 60$.

The results were statistically significant for all comparisons except in men in the PIO versus SU comparison.

We chose second-line $\mathrm{SU}$ as our comparator as this cohort is similar in disease duration and severity to the second-line TZD cohorts. This study design minimises the effect of channelling, a mechanism that leads to confounding by indication, where sicker patients are more likely to be early users of newer drugs. The expected effect of this bias is to increase the association between TZD exposure and insulin use, suggesting that any residual channelling leads to an underestimate of the true effects.

Insulin initiation events per $100 \mathrm{PYs}$ are 3.57 for SU, 1.37 for TZDs, 1.36 for ROS and 1.48 for PIO. Our insulin initiation event rates are lower than other studies have reported. $^{25} 26$ This is likely because we only include T2DM patients following metformin monotherapy. Other studies included TZDs as third-line therapy that likely have a more advanced disease state and are more likely to initiate insulin sooner.

The clinical relevance of our finding, a 90-day delay in the initiation of insulin, must be weighed against the growing body of evidence of increased risk of cardiovascular events associated with TZDs. The ADOPT Trial raises the same issue in monotherapy, where ROS reduced the incidence of monotherapy failure compared to metformin and glyburide but increased the risk of cardiovascular events (including congestive heart failure) versus glyburide. ${ }^{11}$ A 2007 meta-analysis of randomised clinical trial data found a statistically significant $43 \%$ increase in risk of AMI with ROS treatment compared to other oral antidiabetic therapies or placebo. ${ }^{14}$ The RECORD trial found a $15 \%$ higher HR for AMI 
Table 3 Poisson regression for insulin end points associated with thiazolidinediones or sulphonylureas in patients with type 2 diabetes mellitus

\begin{tabular}{|c|c|c|c|c|c|}
\hline \multirow[b]{2}{*}{ Cohort } & \multicolumn{5}{|c|}{ TZDs versus Sulphonylureas } \\
\hline & $\begin{array}{l}\text { Crude rate in } \\
\text { TZD group per } \\
100 \text { PYs }\end{array}$ & $\begin{array}{l}\text { Crude rate in } \\
\text { SU group per } \\
100 \text { PYs }\end{array}$ & $\begin{array}{l}\text { TZD PYs of } \\
\text { follow-up }\end{array}$ & $\begin{array}{l}\text { Crude } \\
\text { rate ratio }\end{array}$ & $\begin{array}{l}\text { Adjusted rate } \\
\text { difference per } 100 \\
\text { PYs }(95 \% \mathrm{CI})\end{array}$ \\
\hline Men, age $\geq 60$ & 0.54 & 2.35 & 734 & 0.23 & $-0.80(-1.51$ to -0.08$)$ \\
\hline Men, age $<60$ & 1.73 & 3.75 & 1271 & 0.46 & $-1.50(-2.44$ to -0.56$)$ \\
\hline Women, age $\geq 60$ & 0.76 & 2.75 & 656 & 0.28 & $-1.18(-2.05$ to -0.32$)$ \\
\hline \multirow[t]{3}{*}{ Women, age $<60$} & 1.94 & 5.91 & 977 & 0.33 & $-2.22(-3.46$ to -0.99$)$ \\
\hline & \multicolumn{5}{|c|}{ Pioglitazone (PIO) versus sulphonylureas } \\
\hline & $\begin{array}{l}\text { Crude rate in } \\
\text { PIO group per } \\
100 \text { PYs }\end{array}$ & $\begin{array}{l}\text { Crude rate in } \\
\text { SU group per } \\
100 \text { PYs }\end{array}$ & $\begin{array}{l}\text { PIO PYs of } \\
\text { follow-up }\end{array}$ & $\begin{array}{l}\text { Crude } \\
\text { rate ratio }\end{array}$ & $\begin{array}{l}\text { Adjusted rate } \\
\text { difference per } 100 \\
\text { PYs (95\% Cl) }\end{array}$ \\
\hline$\overline{\text { Men, age } \geq 60}$ & 0.77 & 2.35 & 260 & 0.33 & $-0.73(-1.9$ to 0.43$)$ \\
\hline Men, age $<60$ & 1.92 & 3.75 & 469 & 0.51 & $-1.37(-2.76$ to 0.02$)$ \\
\hline Women, age $>=60$ & 0.42 & 2.75 & 240 & 0.15 & $-1.09(-2.08$ to -0.11$)$ \\
\hline \multirow[t]{3}{*}{ Women, age $<60$} & 2.05 & 5.91 & 341 & 0.35 & $-2.04(-3.79$ to -0.29$)$ \\
\hline & \multicolumn{5}{|c|}{ Rosiglitazone (ROS) versus slphonylureas } \\
\hline & $\begin{array}{l}\text { Crude rate in } \\
\text { ROS group per } \\
100 \text { PYs }\end{array}$ & $\begin{array}{l}\text { Crude rate in } \\
\text { SU group per } \\
100 \text { PYs }\end{array}$ & $\begin{array}{l}\text { ROS PYs of } \\
\text { follow-up }\end{array}$ & $\begin{array}{l}\text { Crude } \\
\text { rate ratio }\end{array}$ & $\begin{array}{l}\text { Adjusted rate } \\
\text { difference per } 100 \\
\text { PYs (95\% Cl) }\end{array}$ \\
\hline Men, age $\geq 60$ & 0.42 & 2.35 & 474 & 0.18 & $-0.81(-1.57$ to -0.06$)$ \\
\hline Men, age $<60$ & 1.62 & 3.75 & 802 & 0.43 & $-1.52(-2.59$ to -0.45$)$ \\
\hline Women, age $\geq 60$ & 0.96 & 2.75 & 415 & 0.35 & $-1.21(-2.31$ to -0.12$)$ \\
\hline Women, age $<60$ & 1.89 & 5.91 & 636 & 0.32 & $-2.27(-3.65$ to -0.89$)$ \\
\hline
\end{tabular}

comparing ROS to a metformin/sulphonylurea combination, although the finding was statistically insignificant due to limited statistical power. ${ }^{27}$ Several populationlevel observational studies have shown that TZD treatment was associated with an increased risk of cardiovascular disease when compared with other oral antidiabetic therapies. $^{29} 30$

A significant strength of our study was the use of the BC PharmaNet database, which captured all oral antidiabetic and insulin prescriptions dispensed at a community pharmacy, regardless of insurance coverage or payer. The completeness of this database allowed for a study design with low misclassification of exposed patients and a high specificity and sensitivity of our outcome, third-line use of insulin.

\section{Limitations}

Our study has data limitations and interpretability issues that warrant discussion. As with most observational pharmaco-epidemiological studies, the use of administrative claims databases is subjected to data quality issues. We have no reason to believe the quality of the $\mathrm{BC}$ administrative health claims database is of inferior data quality compared to similar administrative claims databases in other jurisdictions. The comprehensiveness of the database allows for generalising results to a wide population.
Residual confounding is a limitation of our study due to its non-randomised design. Baseline characteristics of the study cohorts indicate comparable diabetes duration, sex ratio and drug use. The sulphonylurea cohort was older and had higher rates of renal disease and cardiovascular events in the previous 5 years. Family income was unbalanced at the extreme low and high ranges. In the sulphonylurea cohort, $23 \%$ were in the lowest income range (\$0-\$21 250) compared to $12 \%$ of the TZD cohort. The highest income range (>\$97500) contained $6 \%$ of the sulphonylurea cohort versus $12 \%$ of the TZD cohort. This discrepancy is likely due to BC PharmaCare's limited coverage reimbursement of TZD's versus full coverage of sulphonylureas; wealthier patients were more likely to pay out of pocket for TZDs.

\section{CONCLUSION}

Our analysis showed second-line TZD therapy compared to second-line sulphonylurea therapy was associated with a lower incidence of insulin initiation as third-line treatment in patients with type 2 diabetes, with a mean of 90 days. This duration of delay must be weighed against the absence of a proven reduction in morbidity and mortality with TZDs and the known serious cardiovascular risks. 
Acknowledgements The authors have no conflicts of interest to declare. The study was funded by a grant to the University of British Columbia from the British Columbia Ministry of Health. Their support is gratefully acknowledged. Carney and Dormuth had full access to all the data in the study and takes responsibility for the integrity of the data and the accuracy of the data analysis.

Contributors All authors substantially contributed to the conception, design, analysis and interpretation of data, drafting and revising the article for important intellectual content, and gave approval for the final version. Data analysis was performed by Carney, Dormuth.

Funding British Columbia Ministry of Health.

Competing interests None.

Ethics approval The study received ethics approval from the University of British Columbia (UBC CREB Number H02-70020). The BC Ministry of Health approved data access.

Provenance and peer review Not commissioned; externally peer reviewed.

Data sharing statement Statistical code available from the corresponding author at greg.carney@ti.ubc.ca.

\section{REFERENCES}

1. National diabetes fact sheet. 2011. Centers for disease control and prevention web site. http://www.cdc.gov/diabetes/pubs/estimates11. htm (accessed 4 May 2012)

2. Morgan SG, Cunningham C, Hanley G, et al. The British Columbia $R x$ atlas. Vancouver, BC: Centre for Health Service and Policy Research, 2009.

3. Ringborg A, Lindgren $\mathrm{P}$, Yin DD, et al. Time to insulin treatment and factors associated with insulin prescription in Swedish patients with type 2 diabetes. Diabetes Metab 2010;36:198-203.

4. Ringborg A, Lindgren $P$, Martinell $M$, et al. Prevalence and incidence of type 2 diabetes and its complications 1996-2003-estimates from a Swedish population-based study. Diabet Med 2008;25:1178-86.

5. Canadian Agency for Drugs and Technologies in Health. Optimal Therapy Recommendations for the Prescribing and Use of Second-Line Therapy for Patients with Diabetes Inadequately Controlled on Metformin. Optimal Therapy Report-COMPUS 2010;4. http://www.cadth.ca/media/pdf/C1110_OT Reccommendations final e.pdf (accessed 4 May 2012)

6. British Columbia Medical Association Guidelines \& Protocols Advisory Committee. Diabetes care. Victoria, BC, 2010. http://www. bcquidelines.ca/pdf/diabetes.pdf (accessed 10 April 2012)

7. Canadian Diabetes Association. Canadian diabetes association 2008 clinical practice guidelines for the prevention and management of diabetes in Canada. Can J Diabetes 2008;32(Suppl 1):i-S201. Available from http://www.diabetes.ca/files/cpg2008/cpg2008.pdf (accessed 10 April 2012)

8. Dormuth C, Carney G, Carleton B, et al. Thiazolidinediones and fractures in men and women. Arch Intern Med 2009;169:1395-402.

9. Durbin RJ. Thiazolidinedione therapy in the prevention/delay of type 2 diabetes in patients with impaired glucose tolerance and insulin resistance. Diabetes Obes Metab 2004;6:280-5.

10. The DREAM (Diabetes Reduction Assessment with ramipril and rosiglitazone Medication) Trial Investigators. Effect of rosiglitazone on the frequency of diabetes in patients with impaired glucose tolerance or impaired fasting glucose: a randomized controlled trial. Lancet 2006;368:1096-105.
11. Kahn S, Haffner S, Heise M, et al. for the ADOPT Study Group. Glycemic durability of rosiglitazone, metformin, or glyburide monotherapy. N Engl J Med 2006;355:2427-3.

12. Rascati KL, Richards KM, Lopez D, et al. Progression to insulin for patients with diabetes mellitus using the Texas Medicaid database. Clin Ther 2011;33:2016-20.

13. Rothman KJ, Greenland S. Modern epidemiology. 2nd edn Philadephia, PA: Lippincott-Raven, 1998:347.

14. Action to Control Cardiovascular Risk in Diabetes Study Group Gerstein HC, Miller ME, et al. Action to Control Cardiovascular Risk in Diabetes Study Group. (2008) Effects of intensive glucose lowering in type 2 diabetes. N Engl J Med 2008;358: 2545-59.

15. Meinert CL, Knatterud GL, Prout TE, et al. A study of the effects of hypoglycemic agents on vascular complications in patients with adult-onset diabetes. Diabetes 1970;19(Suppl 2):789-830.

16. Nissen SE, Wolski K. Effect of rosiglitazone on the risk of myocardia infarction and death from cardiovascular causes. $N$ Engl J Med 2007;356;2457-71.

17. Williams JI, Young W. Inventory of studies on the accuracy of Canadian Health Administrative Databases. Toronto, ON: Institute for Clinical Evaluative Sciences, 1996.

18. Fowles JB, Lawthers AG, Weiner JP, et al. Agreement between physicians' office records and Medicare Part B claims data. Health Care Financ Rev 1995;16:189-99.

19. Romano PS, Mark DH. Bias in the coding of hospital discharge data and its implications for quality assessment. Med Care 1994:32:81-90.

20. Glynn RJ, Monane M, Gurwitz JH, et al. Agreement between drug treatment data and a discharge diagnosis of diabetes mellitus in the elderly. Am J Epidemiol 1999;149:541-9.

21. Fisher ES, Whaley FS, Krushat WM, et al. The accuracy of Medicare's hospital claims data: progress has been made, but problems remain. Am J Public Health 1992;82:243-8.

22. Obtained online from BCStats, http://www.bcstats.gov.bc.ca/data/ pop/pop/BCPop.asp (accessed 7 May 2012) and reduced by $7 \%$ to account for the federally insured. Nursing home residents and social income recipients are included.

23. Schneeweiss S, Rassen JA, Glynn RJ, et al. High-dimensional propensity score adjustment in studies of treatment effects using health care claims data. Epidemiology 2009;20:512-22.

24. Romano PS, Roos LL, Jollis JG. Adapting a clinical comorbidity index for use with ICD-9-CM administrative data: differing perspectives. J Clin Epidemiol 1993a:46:1075-9.

25. Donnan PT, Steinke DT, Newton RW, et al. Changes in treatment after the start of oral hypoglycaemic therapy in type 2 diabetes: a population-based study. Diabet Med 2002;19:606-10.

26. Best JD, Drury PL, Davis TM, et al. Glycemic control over 5 years in 4,900 people with type 2 diabetes: real-world diabetes therapy in a clinical trial cohort. Diabetes Care 2012;35;1165-70.

27. Home PD, Pocock SJ, Beck-Nielsen H, et al. Rosiglitazone evaluated for cardiovascular outcomes in oral agent combination therapy for type 2 diabetes (RECORD): a multicentre, randomized, open-label trial. Lancet 2009373:2125-35;.

28. Home PD, Pocock SJ, Beck-Nielsen $\mathrm{H}$, et al. Rosiglitazone evaluated for cardiovascular outcomes-an interim analysis. $N$ Engl J Med 2007;357:28-38.

29. Lipscombe LL, Gomes T, Levesque LE, et al. Thiazolidinediones and cardiovascular outcomes in older patients with diabetes. J Am Med Assoc 2007;298:2634-43.

30. Dormuth CR, Maclure M, Carney G, et al. Rosiglitazone and myocardial infarction in patients previously prescribed metformin PLoS One 2009:4:e6080. 